THE KURUME MEDICAL JOURNAL Vol.12, No.1, 1965

\title{
ELECTRON MICROSCOPIC OBSERVATION OF THE LIVER IN GILBERT'S DISEASE
}

\author{
KYUICHI TANIKAWA AND TAKESHI EMURA \\ The Second Defartment of Medicine, Kurume University School of Medicine, \\ Kurume, Jafan
}

(Received for publication April 28, 1965)

The term "Gilbert's disease" is today applied to a heterogenous group of benign disorder, which is characterized by low grade chronic unconjugated hyperbilirubinemia not due to overt hemolysis.

Recently much attention has been paid to this disorder because it offers clues as to the mechanism of jaundice or bilirubin metabolism. This report is devoted to the electron microscopic observation of the liver in this disorder and a discussion concerning the mechanism of jaundice in this disease.

\section{MATERIALS AND METHODS}

A liver biopsy specimen was taken from a 24 year old female, diagnosed as Gilbert's disease. This patient, with a past history of two episodes of mild jaundice, was admitted to our hospital because of the third onset of mild jaundice. Liver function tests revealed no abnormalities except unconjugated hyperbilirubinemia (total 5.68 $\mathrm{mg} / \mathrm{dl}$, indirect $4.56 \mathrm{mg} / \mathrm{dl}$ ) and a slightly increased B. S.P. retention (10\% in $45 \mathrm{~min}$ ). Hematolçical examinations including erythrccyte fragility and reticulocyte count wese normal. No family history of jaundice or past history of obvious infectious hepatitis was obtained.

For electron microscopy, the liver biopsy specimen was fixed in a cold 1 per cent osmium tetroxide solution, buffered to $\mathrm{pH} 7.4$ with sodium Veronal acetate. The specimen was then dehydrated in graded alcohols and embedded in butyl methacrylate. Ultra-thin sections were cut with a glass knife on Portal-Blum microtome, stained with uranyl acetate, and examined under a HU 11 A electron microscope.

\section{RESULTS}

\section{A) Light microscopic findings (Fig. 1)}

In the section stained with haematoxylin and eosin, the liver cell cords were well preserved. Hepatccytic abnormalities, round cell infiltration, fibrosis or pigment deposition were not noted. 


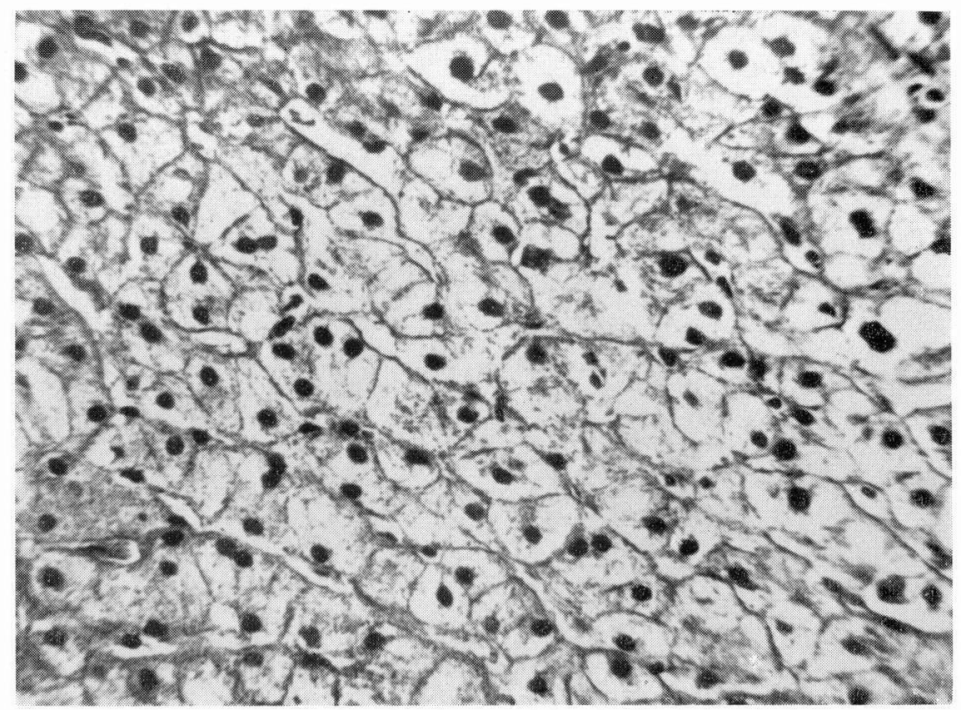

Fig. 1 Light micrograph. Liver cell cords are well preserved and no abnormalities are noted.

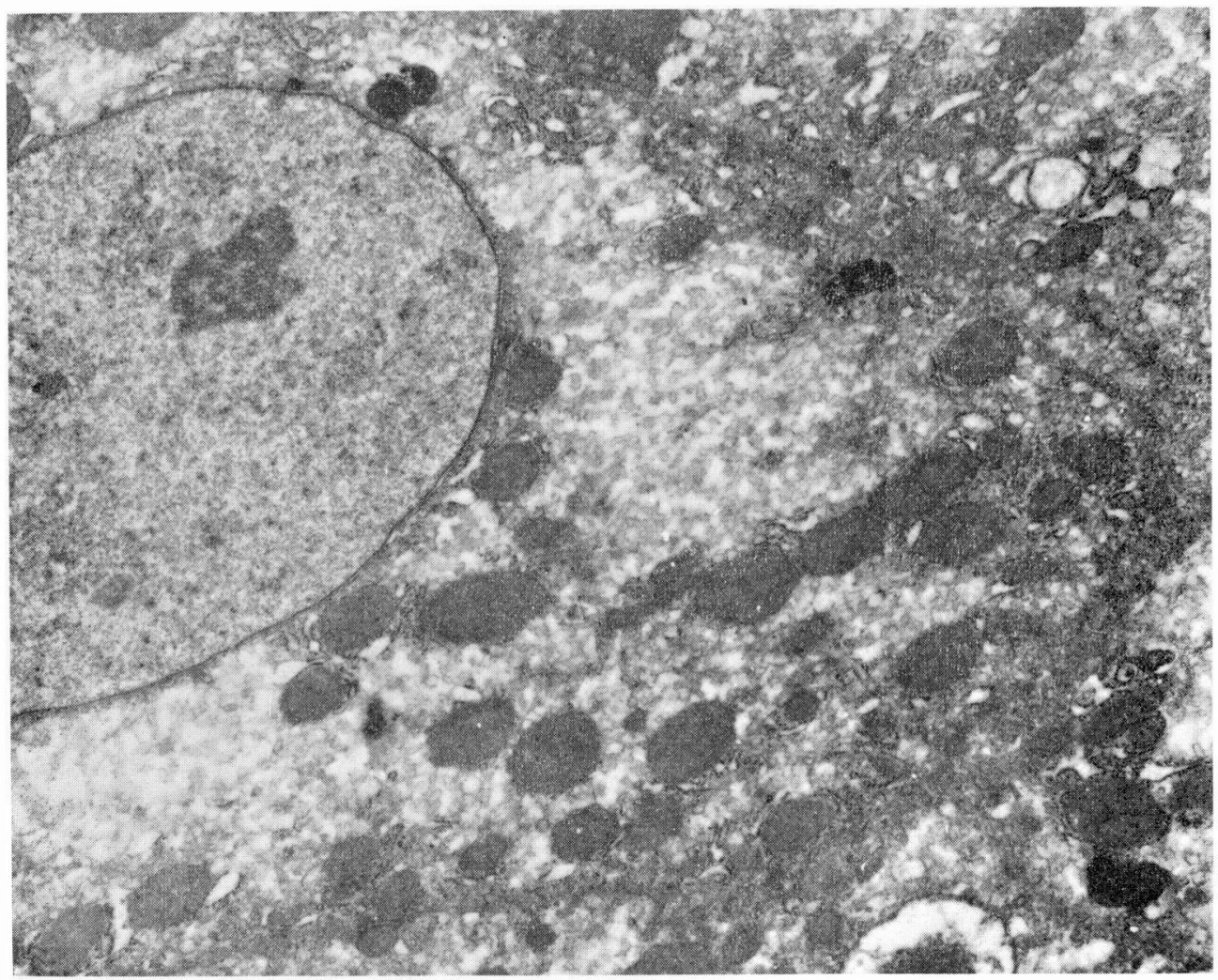

Fig. 2

Electron micrograph. $\times 14000$

Smooth surfaced endoplasmic reticulums are markedly increased in number and the cytoplasm of the liver cell is mostly occupied by them. Rough surfaced ones are scant in number and seen only among mitochondrion. 


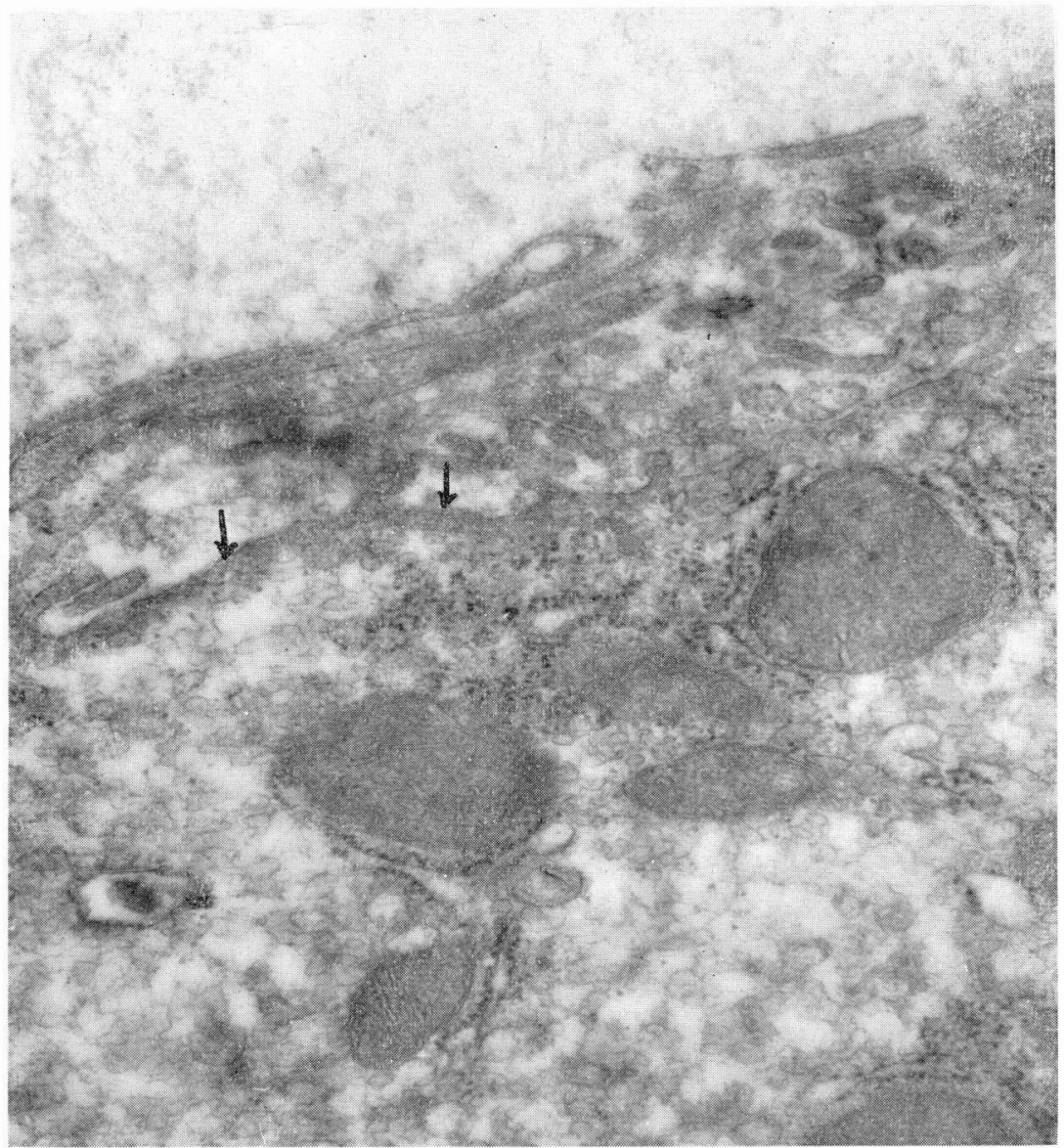

Fig. 3 Electron micrograph. $\times 32000$ Hepatocytic cell membrane (at arrow) facing Disse's space is flattened with loss or stunt of its microvilli. Rough surfaced endoplasmic reticulums reveal to be fairly normal in appearances.

B) Electron microscopic findings (Figs. 2, 3, 4)

Under electron microscope, in general, the liver cell was not markedly changed. However, obvious alterations were observed in the cell membranes facing Disse's space and endoplasmic reticulum in fhe liver cell.

The hepatocytic membrane facing Disse's space appeared to be frequently flattened with loss or stunt of microvilli, yet, no ruptures of the membrane were noted. Endothelial cells showed to be fairly normal.

Smooth surfaced endoplasmic reticulums were markedly increased in number in the cytoplasm of the liver cell, and the cytoplasm appeared to be mostly occupied by them. Under high power magnification, these smooth surfaced profiles of endoplasmic reticulum appeared mostly to be visicular in shape and disrupted or dilated, and no tubular form was observed. Rough surfaced endoplasmic reticulums, on the other hand, were reduced in number and seen only among the mitochondrion, but were normal in appearancese, 


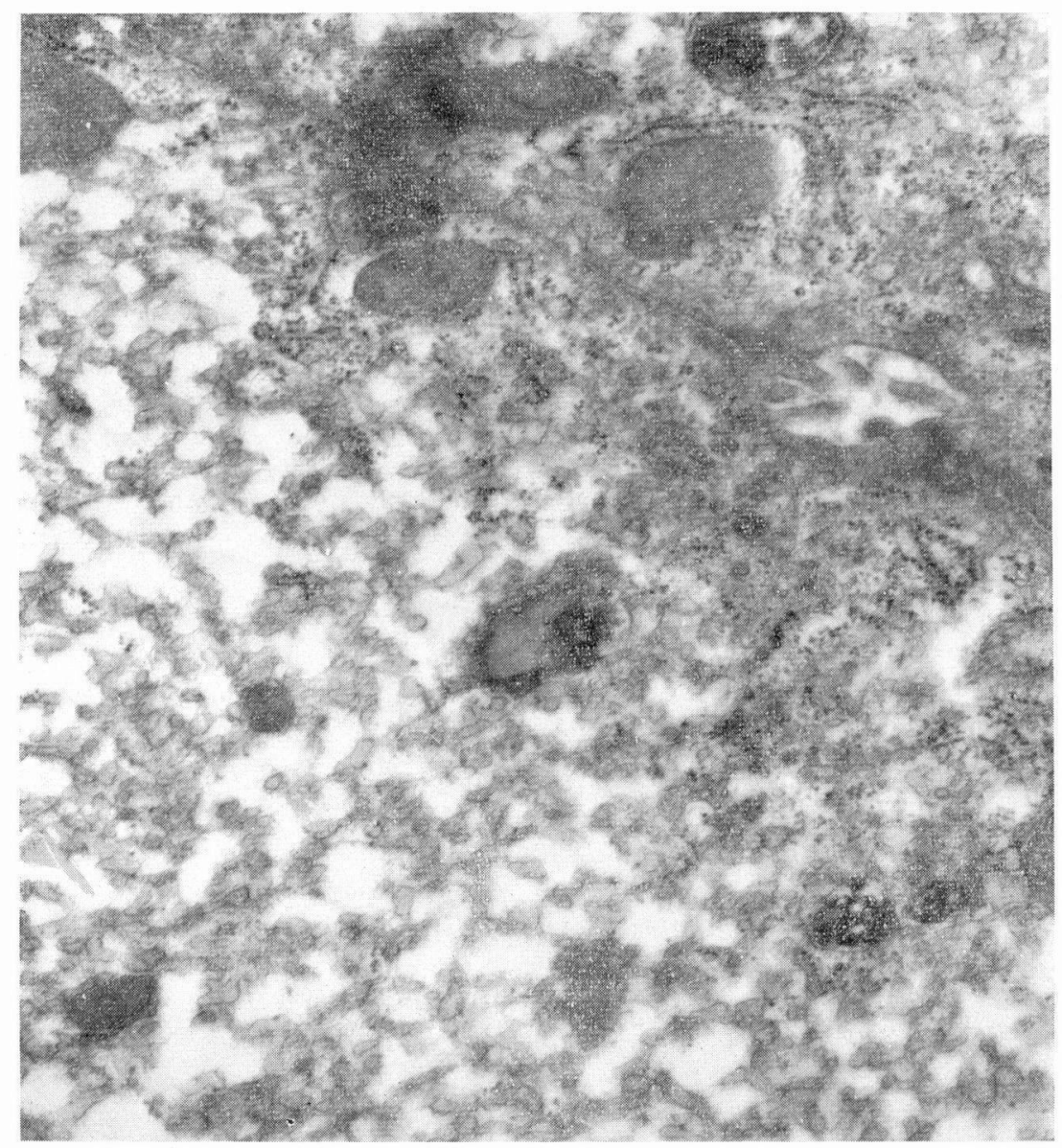

Fig. 4 Electron micrograph. $\times 2503$ J Smooth surfaced endoplasmic reticulums show to be mostly vesicular in shape, disrupted or fragmented. Bile canaliculus is in normal shape.

The mitochondria revealed to be somewhat increased in density and no obvious abnormalities were noted in excretory organelles such as the bile canaliculus and golgi complex. The nucleus showed to be normal.

\section{DISCUSSION}

Gilbert's dissease is probably an inherited disorder. However, similar unconjugated hyperbilirubinemia is also observed at the recovery stage of infectious hepatitis, and no definite differentiation can be made between these disorders except by the history. In the present case, no history of infectious hepatitis was obtained, neither was there histological evidence of residuals of previous hepatitis in the livẹ biopsy specimen in spite of the past two episodes of jaundice, 
Several attempts have been made to demostrate impairment of the conjugating mechanism of the liver in Gilbert's disease, but they have been unsuccessful(1)(2)(3).

Recently a defect in the hepatocytic uptake of bilirubin has been postulated in this disease by several studies through indirect ways(2)(4). Ultrastructural changes in this disease have been reported by $\operatorname{Novikoff(5),~Sasaki(6)}$ and $\operatorname{Simon}(7)$. Sasaki and Ichida(6) found the rough surfaced endoplasmic reticulum to be scant in number and mostly fragmented, while the smooth surfaced endoplasmic reticulum to be markedly increased in the liver cell. Similar changes were observed in the Gunn rat by Novikoff and Essner(5). Our observations have been fairly the same; we did not find any obvious changes in rough surfaced endoplasmic reticulums except a marked reduction in number. However, significant alterations were noted in the increased smooth surfaced ones.

The smcoth surfaced endoplasmic reticulum is known to play an important role in the intracellular transport, and our findings may suggest that smooth surfaced endoplasmic reticulum is compensatively increased because of impaired intracellular transport activity of this orgnelle in this disease.

Simon and Varoner(7) observed rupture of the hepatocytic membrane with disappearance or reduction in number of its microvilli. We were unable to detect any obvious rupture of hepatocytic cell membrane, but the changes of the cell membrane facing Disse's space are in agreement with their observations. The cell membrane of hepatocyte facing Disse's space normally has numerous microvilli, which effectively increase the uptake surface. The changes of this membrane, thus, may imply a defect in hepatocytic uptake of materials from the serum in this disease.

The changes observed in smooth surfaced endoplasmic reticulum in the liver cell and hapatocytic cell membrane facing Disse's space by electron microscope might suggest that this disease is due to an impairment of hepatocytic uptake and intracellular transport of bilirubin, which would substantially elevate unconjugated bilirubin in the serum.

\section{SUMMARY}

A liver biopsy specimen, taken from a 24 year old female with Gilbert's disease, was studied under electron microscope. Markedly increased smooth surfaced endoplasmic reticulums with significant alterations, reduction in number of rough surfaced endoplasmic reticulums and flattening of the hepatocytic cell membrane facing Disse's space with loss of its microvilli were frequently observed. A discussion is made on the possible pathogenesis of this disease.

(Grateful acknowledgement is made to Prof. Okuda for his carefiul review of manuscript) 


\section{REFERENCES}

1) Wakisaka, G. et aL. : Clinical and enzymological observations on cases with Gilbert's disease. Jap. Arch. Int. Med. 8:634-648, 1961.

2) Schmid, R. and Hammaker, L. : Glucuronide formation in patients with constitutional hepatic dysfunction (Gilbert's disease). New Eng. J. Med. 260: 1310-1314, 1959.

3) ARIas, I. M. : Chronic unconjugated hyperbilirubinemia without overt sign of hemolysis in adolescents and adults. J. Clin. Invest. 41: 2233-2245, 1962.

4) Galambos, J.T. and Mac Laren, J.R. : Hepatic uptake defect in patients with "Gilbert's disease". Arch. Int. Med. 111: 214-218, 1963.

5) Novikoff, A.B. ARd Essner, E. : The liver cell. Some new approaches to its study. Am. J. Med. 29: 102-131, 1960.

6) Sasaki, H. and Ichida, F. : Electron microscopic studies of cholestasis. Ann. Report Inst. Virus Res. Kyoto Univ. 4: 172-191, 1961.

7) Simon,G. and Varonier, H.S. : Etude au microscope électronipue de deux cas d'ictère non hemolytique congénital de type Gilbert. Schwaiz, med, Wochschr, 93: 459-465, 1963. 